\title{
Does Household Food Insecurity Affect the Nutritional Status of Preschool Children Aged 6-36 Months?
}

\author{
Mahama Saaka and Shaibu Mohammed Osman \\ School of Medicine and Health Sciences, University for Development Studies, P.O. Box 1883, Tamale, Ghana \\ Correspondence should be addressed to Mahama Saaka; mmsaaka@gmail.com
}

Received 15 February 2013; Revised 7 June 2013; Accepted 10 June 2013

Academic Editor: Sidney R. Schuler

Copyright ( 2013 M. Saaka and S. M. Osman. This is an open access article distributed under the Creative Commons Attribution License, which permits unrestricted use, distribution, and reproduction in any medium, provided the original work is properly cited.

\begin{abstract}
Introduction. This study used three dependent measures of food security to assess the magnitude of household food insecurity and its consequences on the nutritional status of children 6-36 months in Tamale Metropolis of Northern Ghana. Methods. An analytical cross-sectional study was conducted on a sample of 337 mother/child pairs in June 2012. Food access was measured as household food insecurity access scale (HFIAS), household dietary diversity score (HDDS), and food consumption score (FCS). Results. The magnitude of household food insecurity depended on the food access indicator, with HFIAS yielding the highest household food insecurity of $54 \%$. Of the three food access indicators, 30-day HFIAS was not related to any of the nutrition indices measured. HDDS and FCS were both significantly associated with BMI of mothers and chronic malnutrition (stunted growth) but not acute malnutrition (wasting) with FCS being a stronger predictor of nutritional status. Compared to children in food insecure households, children in food secure households were $46 \%$ protected from chronic malnutrition (OR $=0.54,95 \%$ CI: 0.31-0.94). Conclusions and Recommendations. The results of this study show that different measures of household food insecurity produce varied degree of the problem. Efforts at reducing chronic child malnutrition should focus on improving the adequacy of the diet.
\end{abstract}

\section{Introduction}

Child undernutrition continues to be a major public health problem in developing countries including Ghana. According to the Ghana Demographic and Health Survey, there is substantial regional variation of malnutrition in Ghana, with some of the poorest indicators found in the Northern part of the country. The estimated prevalence of chronic malnutrition, for example, in the Northern Region is $32.4 \%$ compared with a national average of $28 \%$ [1]. A recent UNICEF Multiple Indicator Cluster Survey (MICS) conducted in 2011 showed that the prevalence of chronic undernutrition in northern region of Ghana has increased from $32 \%$ in 2008 to $37 \%$ in 2011 [2]. According to the WHO (2000) classification of malnutrition, the malnutrition situation can be described as serious state in the northern region.

The persistent prevalence of chronic malnutrition in Northern Ghana is of particular concern that requires urgent attention and immediate action. To be able to address the problem adequately, it is important that the context-specific risk factors for malnutrition are identified for appropriate interventions to be implemented. The risk factors of malnutrition are multifaceted and complex, and the relative importance of each of the known risk factors of malnutrition including household food insecurity is likely to vary between settings. Food insecurity is probably one of the determinant factors of malnutrition in developing countries, but its role remains unclear. In particular, it is not known whether all children suffer from household food insecurity and at what extreme levels. Some studies have shown that in times of food insecurity, mothers are likely to reduce their own intakes to secure those of infants and small children $[3,4]$.

Food insecurity refers to limited or uncertain availability of nutritionally adequate and safe foods, or limited or uncertain ability to acquire food in socially acceptable ways [5]. The access component of food insecurity comprises three core domains, namely, anxiety and uncertainty about household food supply, insufficient quality of food, and insufficient food intake by household members [6-8]. 
Though there are reported cases of household food insecurity in Northern Ghana, its contribution to child malnutrition remains unclear. To reach any conclusions about whether household food insecurity is independently associated with child malnutrition calls for further investigation. It is on the basis of this that this study used three dependent measures of food insecurity to assess the magnitude of household food insecurity and its consequences on the nutritional status of children 6-36 months and their mothers in Tamale Metropolis in Northern Ghana.

\section{Materials and Methods}

2.1. Study Design and Sampling Procedures. An analytical cross-sectional study was conducted on a sample of 337 mother/child pairs in June 2012. The required sample size was calculated based on the standard formula for one point sample estimation. The primary outcome variable used to estimate the sample size was the population proportion of the chronic malnutrition in the study area. A sample size of 323 was required to ensure that the estimated prevalence of the main outcome variable was within plus or minus $5 \%$ of the true prevalence at 95\% confidence level. An additional 11 was added to take care of nonresponses and other unexpected events (e.g., damaged/incomplete questionnaire), and so the final sample size was adjusted to 341 .

A $30 \times 11$ two-stage cluster sampling procedure was used to include households within clusters that were selected based on the probability-proportional-to-size method. In the first stage of sampling, 30 clusters were selected from a master list of communities (sampling frame) constructed originally by the 2000 Ghana Population and Housing Census and updated by the Metropolitan Health Directorate. The second stage of the sampling involved selecting 11 households from each cluster. Households were selected by the spin-a-pen random walk method. If a selected household had more than one child aged 0 to 36 months, only the youngest child was included in the survey.

2.2. Study Population. The study population comprised women within the reproductive age bracket ( 15 to 45 years) with children aged 6 to 36 months resident in both rural and urban communities. Mother/child pairs were chosen at the household level.

2.3. Data Collection. Household face-to-face interviews using structured questionnaires were used to collect data on household sociodemographic characteristics, food insecurity, child feeding practices, anthropometric measurements of height, weight, and household assets wealth, and details of which are described below.

2.4. Assessment of Household Food Security. Food access was measured through household food insecurity access scale (HFIAS), the household dietary diversity score (HDDS), and food consumption score (FCS).

The concept of food security has been defined variously over the years. One of such definitions was given by the
FAO as "food security" is achieved when it is ensured that "all people, at all times, have physical, social, and economic access to sufficient, safe, and nutritious food which meets their dietary needs and food preferences for an active and healthy life" [9]. Food insecurity therefore exists whenever people are not able to access sufficient food at all times for an active and healthy life.

As defined by the United States Agency for International Development (USAID), food security has three components: availability, access, and utilization. Household food access is defined as the ability to acquire sufficient quality and quantity of food to meet all household members' nutritional requirements for productive lives. We measured food access by using the household food insecurity access scale (HFIAS), the household dietary diversity score (HDDS), and food consumption score (FCS) indicators. Both the HDDS and FCS were assessed using 7-day reference period, whilst the HFIAS is based on a 30-day recall period. Dietary diversity at the household level gives a measure of household food security. The HDDS tool inquired about consumption from 12 food groups.

Food consumption score (FCS) was measured based on dietary diversity, food frequency, and the relative nutritional importance of nine different food groups. Dietary recall questionnaires were used to collect information on the consumption of selected food groups common in Ghana. The interviewees were asked about frequency of consumption (in days) over a recall period of the past 7 days. FCS was calculated using the formula proposed by WFP and FAO of 2008. In this formula, FCS was derived by multiplying the weight for each food type by the frequency (number of days) these food groups were consumed; the values for all food types consumed during the seven days were summed up to give the FCS, thus,

$$
\begin{aligned}
\text { FCS }= & a \times f(\text { staple })+a \times f(\text { pulse })+a \times f(\text { vegetables }) \\
& +a \times f(\text { fruit })+a \times f(\text { animal })+a \times f(\text { sugar }) \\
& +a \times f(\text { dairy })+a \times f(\text { oil })
\end{aligned}
$$

where FCS $=$ food consumption score, $f=$ frequencies of food consumption $=$ number of days for which each food group was consumed during the past 7 days, $a=$ weight/nutritional value of each food group.

Food groups were assigned different weights reflecting their nutritional density-nutrient-dense foods such as meats and dairy products that have higher weights than staples, fruits, and sugar.

The FCS has thresholds consumption categories of "poor," "borderline," and "acceptable."

The FCS indicator is expected to provide a more accurate measure of the quality of the household diet because it accounts for nutritional value of food in addition to the number of different types of food consumed.

The HFIAS was developed for use in developing country settings, and it is a tool that asks respondents about three domains of food insecurity: (1) experiencing anxiety and uncertainty about the household food supply; (2) altering 
quality of the diet; (3) reducing quantity of food consumed [8]. The tool consists of nine questions that ask about changes households made in their diet or food consumption patterns due to limited resources to acquire food in the preceding 30 days.

Based on the responses given to the nine questions and frequency of occurrence over the past 30 days, households are assigned a score that ranges from 0 to 27. A higher HFIAS score is indicative of poorer access to food and greater household food insecurity. For this analysis, households were classified into two groups based on overall distribution of the HFIAS in the sample. The lower the score, the most food secured a household was. Consequently, a score of $<17$ was classified as food secured and a score of $\geq 17$ was classified as food insecure. HFIAS allows assessment of food poverty (i.e., the inability to obtain healthy affordable food).

Dietary diversity has been defined as the number of individual food items or food groups consumed over a given period of time [10] and the reference period can vary, but is most often the previous day or week [11, 12]. Household dietary diversity score (HDDS) is a measure of the total number of different food groups eaten in the previous 24 hours by any household member at home, including food prepared at home but eaten outside, such as a sack lunch [13, 14]. This measure is a reflection both of food availability and in particular of food access, on the premise that households consume a variety of foods when they have the means to acquire them.

Our respondents were asked to recall all foods consumed by any household member in the past 7 days. Then the HDDS was derived on the basis of the number of food groups consumed within the 7-day recall period from the total of 13 food groups. The food group consumption frequency score (FGFS) was calculated by assigning a score of 0 if not consumed during the previous week, 1 if consumed for 1-3 days, and 2 if consumed for at least 4 days. This composite index of dietary diversity takes into account the weekly food frequency and it varied from a minimum of 0 to a maximum of 26 . There are no internationally accepted cut points and thresholds below those cut points to assist in making judgments on whether households below a certain HDDS score have low dietary diversity or not. We classified households into two categories: low HDDS if FGFS was $<15$ and high if $\geq 15$. The cutoff of 15 was chosen because that was the mean FGFS in our sample.

2.5. Determination of Household Economic Status (SES). A household wealth index based on household assets and housing quality was used as a proxy indicator for socioeconomic status (SES) of households. An absolute measure of household wealth (wealth index) used in this study is based on an earlier concept developed by Garenne and Hohmann [15], whereby the sum of dummy variables are created from information collected on housing quality (floor, walls, and roof material), availability of potable water and type of toilet facility, and ownership of household durable goods and livestock (e.g., bicycle, television, radio, motorcycle, sewing machine, telephone, cars, refrigerator, mattress, bed). These facilities or durable goods are often regarded as modern goods that have been shown to reflect household wealth. A household of zero index score, for example, means that household had not a single modern good. The scores were thus added up to give the proxy household wealth index. The index varied from 0 to 18 . Households that had a wealth index score of 13 and below were classified as having a low wealth index score and those that had a wealth index score of 14 and above were classified as having a high wealth index score.

2.6. Anthropometric Measurements and Reference Values. Anthropometric measurements of children were taken and WHO AnthroPlus was used to compute nutrition indices and the results were classified according to World Health Organization 2006 cut-off points. Underweight, wasting, and stunting among children were defined as WAZ, WHZ, and HAZ less than 2 SD below the 2006 WHO growth standards, respectively [16]. Women's nutritional status was assessed by collecting data on the weight and height of nonpregnant, nonlactating women 15-49 years. The children and their mothers were weighed with a SECA electronic scale sensitive to the nearest $100 \mathrm{~g}$. The recumbent length of children less than two years of age (i.e., up to and including 23 months) was measured to the nearest $0.1 \mathrm{~cm}$ with a portable infantometer. A specialized wooden device (i.e., an infantometer) was used. The child was placed on his/her back between the slanting sides. The head was placed so that it is against the top end. The knees were gently pushed down by a helper. For children aged 24-59 months and adults, stature was measured in a standing position. The child stood without shoes on a level floor. The legs were placed together, as also were the heels.

2.7. Body Mass Index. The nutritional status of adult women was assessed using the body mass index (BMI). Maternal weight was measured twice, to the nearest $0.1 \mathrm{~kg}$, with a digital scale, while the subjects were wearing light clothing and no shoes. BMI as an indicator of the nutritional status of adults reflects chronic energy deficiency that was assessed by dividing an individual's weight $(\mathrm{kg})$ by height in metres squared $\left(\mathrm{m}^{2}\right)$. A BMI < 18.5 for nonpregnant, nonlactating women $15-$ 49 years was categorized as underweight or chronic energy deficiency. A BMI over 18.5 indicates adequate nutrition, whilst a BMI between 25 and 30 indicates overnutrition. A very high energy (obesity) intake is expressed by a BMI of $>30$.

2.8. Training of Data Enumerators. Six data enumerators were given training prior to the survey. The training agenda included survey purpose, sampling procedures, field procedures (random household selection, introduction, and systematic data collection), techniques in interviewing, and taking measurements (height and weight). This was aimed at pretesting of questionnaire and achieving high data precision and accuracy.

Anthropometric data quality was validated using the plausibility check function of the SMART for Emergency Nutrition Assessment (ENA) software. The overall scoring of the plausibility check of the data was $10 \%$ and this is acceptable. The validity (plausibility) checks showed, for 
TABLE 1: Characteristics of households stratified by household food insecurity status as measured by low household dietary diversity.

\begin{tabular}{|c|c|c|c|c|}
\hline Factor & $N$ & Food secure households $n(\%)$ & Food insecure households $n(\%)$ & Test statistic \\
\hline \multicolumn{5}{|c|}{ Household wealth index } \\
\hline Low & 95 & $11(11.6)$ & $84(88.4)$ & \multirow{3}{*}{$\chi^{2}=43.4, P<0.001$} \\
\hline High & 241 & $122(50.6)$ & $119(49.4)$ & \\
\hline Total & 336 & $133(39.6)$ & $203(60.4)$ & \\
\hline \multicolumn{5}{|c|}{ Place of residence } \\
\hline Urban & 165 & $97(58.8)$ & $68(41.2)$ & \multirow{3}{*}{$\chi^{2}=50.0, P<0.001$} \\
\hline Rural & 171 & $36(21.1)$ & $135(78.9)$ & \\
\hline Total & 336 & $133(39.6)$ & $203(60.4)$ & \\
\hline \multicolumn{5}{|c|}{ Maternal education level } \\
\hline Nil & 235 & $80(34.0)$ & $155(66.0)$ & \multirow{4}{*}{$\chi^{2}=15.3, P<0.001$} \\
\hline Low & 76 & $35(46.1)$ & $41(53.9)$ & \\
\hline High & 25 & $18(72.0)$ & $7(28.0)$ & \\
\hline Total & 336 & $133(39.6)$ & $203(60.4)$ & \\
\hline \multicolumn{5}{|c|}{ Source of potable water } \\
\hline Protected & 264 & $225(85.2)$ & $39(14.8)$ & \multirow{3}{*}{$\chi^{2}=25.8, P<0.001$} \\
\hline Unprotected & 71 & $41(57.7)$ & $30(42.3)$ & \\
\hline Total & 335 & $266(79.4)$ & $69(20.6)$ & \\
\hline
\end{tabular}

example, that the values for standard deviation (SD) of the $\mathrm{z}$-scores for weight for height $\mathrm{z}$-score (WHZ) and height for age $\mathrm{z}$-score (HAZ) were all within acceptable limits (i.e., less than 1.2). The SD of WHZ should not exceed 1.2 in a good survey. The weight and height measurements were without digit preference. All of these suggest that the data have been well taken and were of good quality.

2.9. Data Management and Analysis. The ENA software ( 2010 version) was used in the data analysis and to check the plausibility of anthropometric data. Anthropometric measurements such as height, weight, and age of children 6-59 months were converted into $\mathrm{z}$-scores using the $2006 \mathrm{WHO}$ reference growth curves. Before performing the anthropometric calculations for weight-for-height (WH), height-forage (HA), and weight-for-age (WA), the data was cleaned and the outliers were removed. The literature recommends that the percentage of outliers should not exceed $2 \%$ of the sample.

The data were analyzed using PASW version 18. We compared three measures of food insecurity to one another and to the measured child anthropometric indicators. For continuous outcomes, statistical significance was assessed using ANOVA. For categorical and dichotomous outcomes, chi-square tests were used to assess statistical significance. Logistic stepwise regression was used to assess the independent contribution of food insecurity to undernutrition. Independent variables considered for entry into the regression models were identified during bivariate correlations analysis. Multicollinearity between independent variables was checked and eliminated. Three of the independent variables exhibited multicollinearity: household wealth index, food consumption score (FCS), and household dietary diversity score (HDDS). So only the variable most highly correlated with the outcome variable of interest was entered into the regression model.
2.10. Ethics Consideration. The study protocol was presented to the Ethics Committee of the School of Medicine and Health Sciences, University for Development Studies, for approval. Permission for data collection was obtained from the local leaders in the respective communities, and verbal informed consent was obtained from each respondent before interviews were conducted. The study's purpose and objectives were explained to each participant prior to interview. Study participants were free to refuse or withdraw from the study at any time.

\section{Results}

3.1. Sociodemographic Characteristics of Study Sample. The study comprised 337 mother/child pairs out of which $50.9 \%$ of them (171) were resident in rural setting. One child had missing height measure. This resulted in a final sample size of 336 for some of the anthropometric indicators. The mean age of the children was $17.7 \pm 9.2$ months and $54.5 \%$ (183) of children were males. The other details of the sample characteristics including maternal age distribution and maternal educational level are contained in Table 1. Foodinsecure households had generally lower socioeconomic status as measured by household wealth index than foodsecure households. A greater proportion of mothers from foodinsecure households had no formal education, compared to mothers from foodsecure households. More foodinsecure households than foodsecure households were resident in rural areas. In comparison to foodsecure households, households with food insecurity have less access to protected potable water.

3.2. Magnitude of Household Food Insecurity and Malnutrition. Table 2 shows the prevalence of child undernutrition and household food insecurity. The magnitude of malnutrition among children in the sample was quantified using 
TABle 2: Prevalence of malnutrition and household food insecurity.

\begin{tabular}{lccc}
\hline Indicator & $N$ & Prevalence n (\%) & 95\% Confidence interval (CI) \\
\hline Household food insecurity (HDDS) & 337 & $134(39.8)$ & $34.4-41.6$ \\
Household food insecurity (HFIAS) & 337 & $182(54.0)$ & $48.5-59.3$ \\
Household food insecurity (FCS) & 337 & $69(20.5)$ & $16.1-24.8$ \\
Underweight (WAZ $<-2$ SD) & 337 & $91(27.0)$ & $22.3-32.3$ \\
Acute malnutrition (WHZ $<-2$ SD) & 336 & $45(13.4)$ & $10.5-16.9$ \\
Chronic malnutrition (HAZ $<-2$ SD) & 336 & $100(29.8)$ & $24.3-35.8$ \\
\hline
\end{tabular}

three anthropometric indicators: weight-for-height (acute), height-for-age (chronic), and weight-for-age (underweight). The magnitude of food insecurity depended on the food access indicator, with HFIAS yielding the highest proportion household food insecurity.

\subsection{Relation between HDDS, FCS, HFIAS, and Household} Wealth Index. All three food access indicators were related to socioeconomic status (SES) as measured by household wealth index (HWI). HWI associated negatively with HFIAS but positively with FGFS and FCS (Table 3 ). Generally, HFIAS was negatively associated with both FCS and FGFS. Higher household dietary diversity is associated with greater food access as measured by the HFIAS.

\subsection{Nutritional Status Indices and Household Food Insecurity.} Of the three food access indicators, HFIAS was not related to any of the nutrition indices measured. As shown in Tables 4 and 5, HDDS and FCS were significantly associated with chronic malnutrition and BMI of mothers with FCS being a stronger predictor of nutritional status. Compared to food secure households, children from food insecure households had lower mean HAZ. The association between chronic malnutrition and HDDS/FCS was stronger in the 24-36 months age group. They were, however, not associated with acute (wasting) malnutrition and underweight. The nutritional status of young children (6-23 months) was less sensitive to changes in food access compared to other age groups ( $\geq 23$ months). In other words, the relationship between food insecurity and chronic under-nutrition was stronger among children aged at least 23 months $F(1,96)=5.7, P=0.019$.

Compared to households with stunted children, the mean household wealth index, FCS and HDDS were significantly higher in households with normal children (Table 6).

Bivariate analyses showed that a number of factors were associated with the mean HAZ (Table 7).

In a multiple regression (stepwise method), only maternal BMI and FCS were important determinants of mean HAZ. As shown in Table 8 , a unit increase in BMI led to 0.15 standards units increase in HAZ $(\beta$-coefficient $=0.15)$. Household wealth index was also a predictor of mean HAZ. There was collinearity between household wealth index and FCS and was thus not entered in the regression analysis.

Other independent variables entered into equation but found to be insignificant were maternal educational levels, sources of potable water, place of residence, FGFS, and timely initiation of breastfeeding.
In logistic multiple regression analysis, only household food insecurity as measured by FCS remained independent significant predictor of chronic malnutrition. Compared to children in food insecure households, children in secure households were $46 \%$ protected from chronic malnutrition $(\mathrm{OR}=0.54,95 \%$ CI: $0.31-0.94)$. So FCS consistently predicted mean HAZ as well as the prevalence of chronic malnutrition.

\section{Discussion}

The purpose of this study was to investigate the magnitude of household food insecurity and its relationship with nutritional status of mothers and their children aged 636 months in Tamale Metropolis of Northern Ghana. We used three food insecurity instruments to measure household food insecurity. Food security has three components, namely, availability, access, and utilization. Household food access, which is defined as the ability to acquire sufficient quality and quantity of food to meet all household members' nutritional requirements for productive lives, is therefore a key component of food security. Food access is measured in a number of ways including quantitative food consumption surveys or income and expenditure analyses, but some of these approaches are time consuming and require sophisticated analytic methods. To address these difficulties, simpler proxy measures of food access including HFIAS, FCS, and HDDS have been developed $[17,18]$ and are being promoted. These food access indicators are expected to distinguish households with different levels of vulnerability to food insecurity. Inadequate food insecurity is one of the three underlying causes of malnutrition and one would therefore expect to see a link between indicators of food insecurity and that of malnutrition. The complexity of food security makes it difficult to measure adequately because different dimensions of it do exist and researchers have tried over the years to capture as much as possible these different dimensions. Food security encompasses accessibility, adequacy, stability, and sustainability of food supply $[19,20]$.

4.1. Magnitude of Household Food Insecurity and Malnutrition. The dominant form of malnutrition among children in the sample was stunted growth and nearly $30 \%$ of the children were suffering from this. According to the findings of the study, the prevalence of global stunting continues to be high in terms of public health significance. The findings are consistent with the results of a recent Multiple Cluster Indicator Survey (MICS) of 2011 conducted in three regions 
TABLE 3: Relationship between household wealth index and food access indicators.

\begin{tabular}{|c|c|c|c|c|}
\hline & Household wealth index & HFIAS & FGFS & FCS \\
\hline \multicolumn{5}{|l|}{ Household wealth index } \\
\hline Pearson correlation & 1 & $-0.24^{* *}$ & $0.47^{* *}$ & $0.32^{* *}$ \\
\hline Sig. (2-tailed) & & $<0.001$ & $<0.001$ & $<0.001$ \\
\hline$N$ & 336 & 336 & 336 & 336 \\
\hline \multicolumn{5}{|l|}{ HFIAS } \\
\hline Pearson correlation & $-0.24^{* *}$ & 1 & $-0.19^{* *}$ & $-0.18^{* *}$ \\
\hline Sig. (2-tailed) & $<0.001$ & & 0.001 & 0.001 \\
\hline$N$ & 336 & 336 & 336 & 336 \\
\hline \multicolumn{5}{|l|}{ FGFS } \\
\hline Pearson correlation & $0.47^{* *}$ & $-0.19^{* *}$ & 1 & $0.45^{* *}$ \\
\hline Sig. (2-tailed) & $<0.001$ & 0.001 & & $<0.001$ \\
\hline$N$ & 336 & 336 & 336 & 336 \\
\hline \multicolumn{5}{|l|}{ FCS } \\
\hline Pearson correlation & $0.32^{* *}$ & $-0.18^{* *}$ & $0.45^{* *}$ & 1 \\
\hline Sig. (2-tailed) & $<0.001$ & 0.001 & $<0.001$ & \\
\hline$N$ & 336 & 336 & 336 & 337 \\
\hline
\end{tabular}

${ }^{* *}$ Correlation is significant at the 0.01 level (2-tailed).

TABLE 4: Nutritional status indices and household food security as measured by household dietary diversity score (HDDS).

\begin{tabular}{|c|c|c|c|c|c|c|}
\hline \multirow{2}{*}{ Anthropometric measurement } & \multirow{2}{*}{$N$} & \multirow{2}{*}{ Mean } & \multirow{2}{*}{ Std. deviation } & \multicolumn{2}{|c|}{ 95\% Confidence interval for mean } & \multirow{2}{*}{ Test statistic } \\
\hline & & & & Lower bound & Upper bound & \\
\hline \multicolumn{7}{|l|}{ BMI of adults (women) } \\
\hline Low HDDS $(<15)$ & 203 & 23.1 & 4.14 & 22.51 & 23.66 & \multirow{3}{*}{$\begin{array}{l}F(1,335)=4.5 \\
P=0.03\end{array}$} \\
\hline High HDDS (15-21) & 133 & 24.1 & 4.68 & 23.32 & 24.93 & \\
\hline Total & 336 & 23.5 & 4.39 & 23.03 & 23.97 & \\
\hline \multicolumn{7}{|l|}{ WHZ } \\
\hline Low HDDS $(<15)$ & 203 & -0.86 & 1.09 & -1.01 & -0.70 & \multirow{3}{*}{$\begin{array}{l}F(1,333)=0.005 \\
P=0.9\end{array}$} \\
\hline High HDDS (15-21) & 131 & -0.85 & 1.03 & -1.03 & -0.68 & \\
\hline Total & 334 & -0.86 & 1.07 & -0.97 & -0.74 & \\
\hline \multicolumn{7}{|l|}{ HAZ } \\
\hline Low HDDS $(<15)$ & 203 & -1.51 & 1.49 & -1.71 & -1.30 & \multirow{3}{*}{$\begin{array}{l}F(1,333)=4.6 \\
P=0.03\end{array}$} \\
\hline High HDDS (15-21) & 131 & -1.16 & 1.41 & -1.40 & -0.92 & \\
\hline Total & 334 & -1.37 & 1.46 & -1.53 & -1.21 & \\
\hline \multicolumn{7}{|l|}{ WAZ } \\
\hline Low HDDS $(<15)$ & 203 & -1.39 & 1.21 & -1.56 & -1.23 & \multirow{3}{*}{$\begin{array}{l}F(1,333)=0.8 \\
P=0.4\end{array}$} \\
\hline High HDDS (15-21) & 132 & -1.28 & 1.09 & -1.47 & -1.09 & \\
\hline Total & 335 & -1.35 & 1.16 & -1.48 & -1.23 & \\
\hline
\end{tabular}

of Northern Ghana, in which prevalence of chronic malnutrition was in the range of $23.1-37.4 \%$ [2]. Interestingly, the magnitude of food insecurity depended on the food access indicator, with HFIAS yielding the highest prevalence of $54.0 \%$ and the lowest prevalence of $20.5 \%$ was given by FCS. Though all indicators measure food access, the approach in measuring them and their sensitivity to identifying food insecure households differ and so one would expect such differences.
4.2. Relation between HDDS, FCS, HFIAS, and Household Wealth Index. It was shown that, in general, all food access indicators were related to socioeconomic status (SES) and could therefore be considered as reasonable proxies for food access. SES was measured by household wealth index (HWI). HWI associated negatively with HFIAS but positively with FGFS and FCS. Generally, HFIAS was negatively associated with both FCS and FGFS. Higher household dietary diversity (HDDS) was associated with greater food access as measured 
TABLE 5: Nutritional status indices and household food security as measured by food consumption score (FCS).

\begin{tabular}{|c|c|c|c|c|c|c|}
\hline \multirow{2}{*}{ Anthropometric measurement } & \multirow{2}{*}{$N$} & \multirow{2}{*}{ Mean } & \multirow{2}{*}{ Std. deviation } & \multicolumn{2}{|c|}{ 95\% Confidence interval for mean } & \multirow{2}{*}{ Test statistic } \\
\hline & & & & Lower bound & Upper bound & \\
\hline \multicolumn{7}{|l|}{ WHZ } \\
\hline Food in-secure & 203 & -0.86 & 1.09 & -1.008 & -0.70 & \multirow{3}{*}{$\begin{array}{l}F(1,332)=0.005 \\
P=0.9\end{array}$} \\
\hline Food secure & 129 & -0.85 & 1.04 & -1.03 & -0.67 & \\
\hline Total & 332 & -0.85 & 1.07 & -0.97 & -0.74 & \\
\hline \multicolumn{7}{|l|}{ HAZ } \\
\hline Food in-secure & 69 & -1.68 & 1.64 & -1.71 & -1.30 & \multirow{3}{*}{$\begin{array}{l}F(1,334)=4.1 \\
P=0.04\end{array}$} \\
\hline Food secure & 266 & -1.29 & 1.41 & -1.40 & -0.91 & \\
\hline Total & 335 & -1.37 & 1.46 & -1.53 & -1.21 & \\
\hline \multicolumn{7}{|l|}{ WAZ } \\
\hline Food insecure & 203 & -1.39 & 1.21 & -1.56 & -1.23 & \multirow{3}{*}{$\begin{array}{l}F(1,332)=0.8 \\
P=0.4\end{array}$} \\
\hline Food secure & 130 & -1.27 & 1.10 & -1.46 & -1.08 & \\
\hline Total & 333 & -1.35 & 1.17 & -1.47 & -1.22 & \\
\hline \multicolumn{7}{|l|}{ BMI of adults (women) } \\
\hline Food in-secure & 203 & 23.09 & 4.14 & 22.51 & 23.66 & \multirow{3}{*}{$\begin{array}{l}F(1,333)=4.9 \\
P=0.028\end{array}$} \\
\hline Food secure & 131 & 24.16 & 4.70 & 23.35 & 24.98 & \\
\hline Total & 334 & 23.51 & 4.39 & 23.04 & 23.98 & \\
\hline
\end{tabular}

TABLE 6: Comparison of mean FCS, HDDS and HFIAS stratified by chronic malnutrition $(N=337)$.

\begin{tabular}{|c|c|c|c|c|c|c|}
\hline & \multirow{2}{*}{$N$} & \multirow{2}{*}{ Mean } & \multirow{2}{*}{ Std. deviation } & \multicolumn{2}{|c|}{ 95\% Confidence interval for mean } & \multirow{2}{*}{ Test statistic } \\
\hline & & & & Lower bound & Upper bound & \\
\hline \multicolumn{7}{|c|}{ Household wealth index } \\
\hline Normal & 235 & 7.6 & 2.0 & 7.3 & 7.9 & \multirow{3}{*}{$\begin{array}{l}F(1,333)=5.6 \\
P=0.018\end{array}$} \\
\hline Stunted & 99 & 6.9 & 2.5 & 6.5 & 7.5 & \\
\hline Total & 334 & 7.4 & 2.2 & 7.2 & 7.7 & \\
\hline \multicolumn{7}{|l|}{ FCS } \\
\hline Normal & 236 & 61.8 & 21.4 & 59.1 & 64.6 & \multirow{3}{*}{$\begin{array}{l}F(1,332)=4.8, \\
P=0.029\end{array}$} \\
\hline Stunted & 99 & 56.2 & 21.5 & 51.9 & 60.5 & \\
\hline Total & 335 & 60.1 & 21.6 & 57.8 & 62.5 & \\
\hline \multicolumn{7}{|l|}{ HDDS } \\
\hline Normal & 235 & 13.6 & 3.5 & 13.1 & 14.0 & \multirow{3}{*}{$\begin{array}{l}F(1,332)=3.2 \\
P=0.07\end{array}$} \\
\hline Stunted & 99 & 12.8 & 3.9 & 12.0 & 13.6 & \\
\hline Total & 334 & 13.3 & 3.7 & 12.9 & 13.7 & \\
\hline \multicolumn{7}{|l|}{ HFIAS } \\
\hline Normal & 235 & 3.9 & 2.1 & 3.6 & 4.1 & \multirow{3}{*}{$\begin{array}{l}F(1,332)=0.5 \\
P=0.48\end{array}$} \\
\hline Stunted & 99 & 4.1 & 2.1 & 3.6 & 4.5 & \\
\hline Total & 334 & 3.9 & 2.1 & 3.7 & 4.2 & \\
\hline
\end{tabular}

by the HFIAS. Food insecurity measured by the HFIAS is linked to poverty levels and it allows assessment of food poverty (i.e., the inability to obtain healthy affordable food). The higher the score, the lower the socioeconomic status. It was found to be inversely correlated with household dietary diversity, that is, households with low dietary diversity score are high for food insecurity, whereas HFIAS identifies consumption patterns that household employ in relation to access to food and can provide information on coping strategies such as going to bed hungry or passing a whole day without food; the HDDS and FCS give indication of the actual food consumed in times of food insufficiency.

Though the HFIAS is a valid measure of food insecurity in several settings [17], it was not associated with chronic malnutrition even among a subgroup of children older than 24 months in our study. Other studies have reported similar insignificant findings on the relationship between HFIAS and nutritional status [21-24].

The lack of association between nutrition indices and HFIAS may be due to several reasons. First, the mothers 
TABLE 7: Determinants of mean HAZ.

\begin{tabular}{|c|c|c|c|c|c|c|}
\hline \multirow{2}{*}{ Determinant } & \multirow{2}{*}{$N$} & \multirow{2}{*}{ Mean } & \multirow{2}{*}{ Std. deviation } & \multicolumn{2}{|c|}{ 95\% Confidence interval for mean } & \multirow{2}{*}{ Test statistic } \\
\hline & & & & Lower bound & Upper bound & \\
\hline \multicolumn{7}{|l|}{ Wealth } \\
\hline Low & 95 & -1.63 & 1.44 & -1.93 & -1.34 & \multirow{3}{*}{$F(1,333)=4.3, P=0.04$} \\
\hline High & 239 & -1.27 & 1.46 & -1.45 & -1.08 & \\
\hline Total & 334 & -1.37 & 1.46 & -1.53 & -1.21 & \\
\hline \multicolumn{7}{|l|}{ Maternal BMI } \\
\hline Underweight & 23 & -1.40 & 1.32 & -1.98 & -.83 & \multirow{5}{*}{$F(1,334)=3.8, P=0.01$} \\
\hline Normal & 208 & -1.48 & 1.48 & -1.68 & -1.28 & \\
\hline Overweight & 77 & -1.37 & 1.33 & -1.67 & -1.06 & \\
\hline Obese & 27 & -0.48 & 1.56 & -1.10 & 0.14 & \\
\hline Total & 335 & -1.37 & 1.46 & -1.52 & -1.21 & \\
\hline \multicolumn{7}{|l|}{ FCS } \\
\hline Food secure & 266 & -1.29 & 1.41 & -1.45 & -1.12 & \multirow{3}{*}{$F(1,334)=4.1, P=0.04$} \\
\hline Food insecure & 69 & -1.68 & 1.64 & -2.08 & -1.29 & \\
\hline Total & 335 & -1.37 & 1.46 & -1.52 & -1.21 & \\
\hline \multicolumn{7}{|l|}{ HDDS } \\
\hline$<15$ (Low) & 203 & -1.51 & 1.49 & -1.71 & -1.30 & \multirow{3}{*}{$F(1,333)=4.6, P=0.03$} \\
\hline 15-21 (High) & 131 & -1.16 & 1.41 & -1.40 & -0.92 & \\
\hline Total & 334 & -1.37 & 1.46 & -1.53 & -1.21 & \\
\hline \multicolumn{7}{|c|}{ Potable water sources } \\
\hline Protected & 262 & -1.26 & 1.47 & -1.44 & -1.09 & \multirow{3}{*}{$F(1,332)=7.0, P=0.008$} \\
\hline Unprotected & 71 & -1.78 & 1.37 & -2.10 & -1.46 & \\
\hline Total & 333 & -1.37 & 1.46 & -1.53 & -1.22 & \\
\hline
\end{tabular}

TABLE 8: Determinants of mean HAZ.

\begin{tabular}{lccccc}
\hline Model & $\begin{array}{c}\text { Standardized coefficients } \\
\text { Beta }\end{array}$ & \multirow{2}{*}{ S } & \multicolumn{2}{c}{ Sig. } & \multicolumn{2}{c}{$\begin{array}{c}\text { L5.0\% Confidence interval for Beta (B) } \\
\text { Upper bound }\end{array}$} \\
\hline (Constant) & & -6.688 & $<0.001$ & -3.91 & -2.13 \\
BMI of adults (women) & 0.15 & 2.735 & 0.007 & 0.01 & 0.09 \\
FCS & 0.12 & 2.108 & 0.036 & 0.001 & 0.015 \\
\hline
\end{tabular}

who were the respondents in this study may have reported similar responses concerning the nine items of this particular household food security scale. In nonemergency situation as in the case of this study, responses to most of the items in this questionnaire were similar and very little variation was seen and that could possibly mask the relationship between food insecurity and under-nutrition. Second, the respondents may not accurately have recalled their feelings and behaviors over the recall period of 30 days vividly. The longer the recall period, the greater the likelihood that respondents will provide inaccurate responses.

However, several studies including a multi-country study, have demonstrated that household food insecurity as measured using the HFIAS or a modified version of significantly related with height-for-age such that children from food insecure households had lower HAZ than children from food secure households [25-28]. The measure of food insecurity based on the HFIAS seeks experience of food security beyond hunger and therefore captures uncertainty, quality, and hunger aspects of food insecurity.

Our results further indicate that household food security as measured by FCS is very much correlated with household wealth index and may thus serve a strong indicator of socioeconomic status (SES). In our sample, FCS was independently associated with under-nutrition. Lower household socioeconomic status was associated with both household food insecurity and chronic under-nutrition among children and adult women.

The specific mechanisms by which poverty leads to food insecurity and child malnutrition are not clear. In a logistic regression analysis, low FCS was highly significant predictor of stunting when it was modeled with other covariates including maternal BMI. When household wealth index, a composite index of housing quality and ownership of household assets, was included in the model, the food security variable lost its statistical significance. That is, households 
with few assets are more likely to experience recurrent poor dietary diversity and also are more likely to have stunted children. Based on these findings, it can be inferred that children's nutritional status in Northern Ghana is strongly and positively related to both household socioeconomic status and food security. Any situation that limits real incomes of families and in the accessibility of food can be expected to result in a substantial stunted growth. This study was conducted in the Tamale Metropolis where most households procure their food supplies through purchases. It is thus understandable that households which produce a major share of the food they consume may be less subject to insecurity than households which depend almost entirely on purchased food. This perhaps partly explains the close links of food insecurity and poverty.

\subsection{Nutritional Status Indices and Household Food Insecurity.} This study presents an important comparison of household food security as measured by three different instruments and child nutritional status. This is perhaps the first study to assess household food insecurity in Ghana using three measurement tools of HFIAS, HDDS, and FCS concurrently and it is also one of the few studies to assess the relationship between household food insecurity and malnutrition among children aged from 6 to 36 months in developing countries setting.

The main finding was that household food insecurity as measured by HFIAS was not associated with any of the anthropometric indices among children aged from 6 to 36 months. However, low HDDS and FCS which are measures of food access and diet quality were significantly associated with chronic child malnutrition and undernutrition of mothers as measured by BMI. The association between chronic malnutrition and low HDDS/FCS was stronger in the 24-36 months age group compared to children aged 623 months. They were, however, not associated with wasting and underweight. This is expected because it is often argued that the nutritional status of very young children may be less sensitive to changes in food availability than is true of other age groups. This stems from the fact that households may reallocate resources when food is scarce to buffer the youngest children from declines in food intakes [29] and because factors other than low food energy intakes may be relatively more important. Households can cope with declines in food availability through multiple mechanisms without necessarily sacrificing nutrient adequacy for vulnerable members [30].

Other studies have shown that household dietary diversity is significantly associated with nutritional status indicators especially among preschool children [31,32] and also a measure of household food security and/or micronutrient adequacy of diets of women of reproductive age [33]. The poor relationship observed between dietary diversity and underweight/wasting indicates that factors other than just diet are responsible for acute malnutrition. It needs to be emphasized that the association observed between chronic malnutrition and household dietary diversity was stronger among older children aged more than 23 months. For the younger age groups 6-23 months, the association was not discernible.
The etiology of malnutrition is very complex and it appears that food insecurity does not necessarily result in malnutrition especially among children less than 24 months. Other factors including recurrent infections, birth weight, and socioeconomic status may be relatively more important as risk factors for malnutrition among these young children. The major underlying causes of growth failure in very young children include inadequate sanitation and hygiene and less than optimal infant and young child feeding practices, as well as lack of food at the household level [34].

Multiple regression analysis showed that household wealth index confounds food insecurity as an independent predictor of chronic malnutrition among children. The significant negative associations between household wealth index and child stunting suggest that poverty may be a major determining factor of the nutritional status of children aged from 6 to 36 months in the study population. Poor families will find it more difficult serving adequate meals.

Research on the relationship between household food insecurity and nutritional status of children has produced mixed results, whereas some studies have reported a positive association between household food insecurity and childhood growth indicators such as weight gain $[35,36]$; others have found negative association $[26,27,37,38]$ with weight and height gains among children. One recent study from Nepal reported that household food insecurity level was not significantly associated with stunting, underweight, or anemia among children less than two years of age after controlling for socioeconomic status, maternal height, education, and infant feeding practice [39]. However, among children under two years in rural Bangladesh, higher food security was associated with better growth outcomes including weight and length gains [38]. Similarly, in Colombia, stunting and underweight among preschool children were significantly inversely associated with household food security, implying that greater food security was associated with lower levels of stunting and underweight [7].

It appears that the measure of food insecurity used and study populations may explain the discrepancies that exist in the literature. As noted in the present study, HFIAS does not appear to be sensitive to changes in nutritional status of children especially those below the age of 24 months.

4.4. Relationship between Food Insecurity Maternal BMI. Maternal BMI was categorized into under-nutrition (defined as BMI $\left.<18.5 \mathrm{~kg} / \mathrm{m}^{2}\right)$, normal weight $\left(\geq 18.5\right.$ and $\left.<25 \mathrm{~kg} / \mathrm{m}^{2}\right)$, and overnutrition $\left(\mathrm{BMI}>25 \mathrm{~kg} / \mathrm{m}^{2}\right)$. In our study sample, women from food insecure households had lower BMI than women who were food secure. BMI was also positively associated with food security indicators that reflected dietary quality (i.e., HDDS and FCS) but was not associated with household food insecurity as measured by HFIAS. Women's BMI has been used in Africa as an indicator of food security [40]. In contrast, most studies conducted especially in developed countries report that food insecure women tend to have higher BMI than women who were food secure [28], but not all studies have reported this relationship [41]. This infers that the percentage of women overweight or obese in severely 
food insecure households was greater than the proportion of women overweight or obese in moderately food insecure households.

The few studies that have been conducted from developing countries among adults and children have produced mixed results. Household food insecurity was associated with obesity among rural women in Malaysia, [42], while in Trinidad and Tobago, household food insecurity was associated with underweight among adults [43]. The evidence is that in low-income countries, obesity is associated with affluence, but in high-income countries, obesity is more often associated with lower socioeconomic status had been reported earlier [44].

Household wealth index (a proxy for socioeconomic status) was also associated with greater odds of overweight or obesity. These associations are consistent with what is commonly seen in developing countries where individuals of higher socioeconomic classes are more at risk of overweight and obesity. One possible explanation for these relationships is that wealthy households in developing countries are more likely of purchasing foods especially those that are energy dense and less likely to exercise. On the other hand, poor families may have less access to such foods and may do more exercise through walking. In the developed countries, the opposite appears to occur, where the wealthy families are able to access more healthy diets including vegetables and less concentrated energy dense foods.

4.5. Summary of Findings. The magnitude of household food insecurity depended on the food access indicator, with HFIAS yielding the highest household food insecurity of 54\%. Of all the three food access indicators used, FCS associated significantly with chronic malnutrition (stunted growth) but not acute malnutrition (wasting).

Mean HAZ was significantly higher in food secure households, compared to food insecure households ( -1.2 versus $-1.5, F(1,331)=4.7, P=0.031)$. Similarly, compared to children in food insecure households, children in secure households were $46 \%$ protected from chronic malnutrition $(\mathrm{OR}=0.54,95 \% \mathrm{CI}:$ 0.31-0.94). Household food insecurity as measured by FCS associated positively with maternal BMI $(F(1,333)=4.9, P=0.028)$.

\section{Conclusion and Recommendation}

Findings from this study strengthen growing evidence that improved household dietary diversity is a proxy measure of household food security/food access and it positively associated with economic ability of a household to access a variety of foods, which goes to improve the nutritional status among young children and mothers. The policy implication of this is that strategies for improved nutritional security should focus on improving the household food security, together with an overall socioeconomic wellbeing of families. Strategies should include behaviour change communication on the consumption of diversified foods alongside supporting families to produce such foods.

\section{Limitation}

The cross-sectional nature of the data limits our ability to draw any causal conclusions. Recall bias was also possible and may explain the high prevalence of household food insecurity. Despite these limitations, our results have shed more light on the association between household food insecurity and the nutritional status of children aged from 6 to 36 months in developing country setting.

\section{Conflict of Interests}

The study was conducted purely on academic grounds and there is no conflict of interests.

\section{Acknowledgments}

The authors wish to acknowledge and thank the contribution by the data enumerators, whose organization and cooperation made it possible to collect the required data for the study. Their warmest compliments also go to all of the women who participated in this study for their immense cooperation. The authors give special thanks also to the community leaders, the data enumerators, the data entry clerks, and the field driver for their selfless contribution and support throughout the study. They are particularly grateful to the District Director of Health Services of Tamale Metropolitan Health Directorate and Dr. Francis Soah Ali for his support and permission to carry out the study in the Metropolis. No funding was received from any source for this study. It was conducted in fulfillment of master's degree in Community Health and Development at the University for Development Studies, Ghana.

\section{References}

[1] Ghana Statistical Service, Ghana Health Service (GHS), and ICF Macro, Ghana Demographic and Health Survey (GDHS), GSS, GHS, and ICF Macro, Accra, Ghana, 2009.

[2] UNICEF and GHS, Multiple Indicator Cluster Survey (MICS), UNICEF, Accra, Ghana, 2011.

[3] M. A. Graham, "Food allocation in rural Peruvian households: concepts and behavior regarding children," Social Science and Medicine, vol. 44, no. 11, pp. 1697-1709, 1997.

[4] O. Kuku, C. Gundersen, and S. Garasky, "Differences in food insecurity between adults and children in Zimbabwe," Food Policy, vol. 36, no. 2, pp. 311-317, 2011.

[5] S. A. Anderson, "Core indicators of nutritional state for difficult-to-sample populations," Journal of Nutrition, vol. 120, no. 11, pp. 1559-1600, 1990.

[6] W. S. Wolfe and E. A. Frongillo, "Building household foodsecurity measurement tools from the ground up," Food and Nutrition Bulletin, vol. 22, no. 1, pp. 5-12, 2001.

[7] J. Coates, E. A. Frongillo, B. L. Rogers, P. Webb, P. E. Wilde, and R. Houser, "Commonalities in the experience of household food insecurity across cultures: what are measures missing?" Journal of Nutrition, vol. 136, no. 5, pp. 1438S-1448S, 2006.

[8] J. Coates, A. Swindale, and P. Bilinksy, Household Food Insecurity Access Scale (HFIAS) for Measurement of Food Access: 
Indicator Guide, Version 2, Food and Nutrition Technical Assistance/Academy for Educational Development, Washington, DC, USA, 2006.

[9] FAO, The State of Food Insecurity in the World, FAO, Rome, Italy, 2000.

[10] M. T. Ruel, "Operationalizing dietary diversity: a review of measurement issues and research priorities," Journal of Nutrition, vol. 133, no. 11, pp. 3911S-3926S, 2003.

[11] FAO, Guidelines for Measuring Household and Individual Dietary Diversity, Food and Agriculture Organization of the United Nations, Rome, Italy, 2011.

[12] World Food Programme (WFP), Comprehensive Food Security \& Vulnerability Analysis Guidelines, United Nations World Food Programme, Rome, Italy, 2009.

[13] FANTA Project, "Household Dietary Diversity Score (HDDS) for Measurement of Household Food Access: Indicator Guide," VERSION 2, 2006, http://www.fantaproject.org/downloads/ pdfs/HDDS_v2_Sep06.pdf.

[14] J. Hoddinott and Y. Yisehac, "Dietary diversity as a food security indicator," FCND Discussion Paper No 136, International Food Policy Research Institute, Washington, DC, USA, 2002.

[15] M. Garenne and S. Hohmann-Garenne, "A wealth index to screen high-risk families: application to Morocco," Journal of Health Population and Nutrition, vol. 21, no. 3, pp. 235-242, 2003.

[16] WHO, WHO Child Growth Standards: Length/Height-for-Age, Weight-for-Age, Weight-for-Length, Weight-for-Height and Body Mass Index-for-Age: Methods and Development, WHO, Geneva, Switzerland, 2006.

[17] A. Swindale and P. Bilinsky, Household Dietary Diversity Score (HDDS) for Measurement of Household Food Access: Indicator Guide Version 2, Food Assistance Nutrition technical assistance Project/Academy for educational Development, Washniton, DC, USA, 2006.

[18] P. Webb, J. Coates, E. A. Frongillo, B. L. Rogers, A. Swindale, and P. Bilinsky, "Measuring household food insecurity: why it's so important and yet so difficult to do," Journal of Nutrition, vol. 136, no. 5, pp. 1404S-1408S, 2006.

[19] A. K. Sen, Ed., Poverty and Famine: An Essay on Entitlement and Deprivation, Clarendon Press, Oxford, UK, 1981.

[20] J. Gittelsohn, S. Mookherji, and G. Pelto, "Operationalizing household food security in rural Nepal," Food and Nutrition Bulletin, vol. 19, no. 3, pp. 210-222, 1998.

[21] K. Alaimo, C. M. Olson, E. A. Frongillo, and R. R. Briefel, "Food insufficiency, family income, and health in US preschool and school-aged children," The American Journal of Public Health, vol. 91, no. 5, pp. 781-786, 2001.

[22] L. L. Kaiser, H. R. Melgar-Quiñonez, C. L. Lamp, M. C. Johns, J. M. Sutherlin, and J. O. Harwood, "Food security and nutritional outcomes of preschool-age Mexican-American children," Journal of the American Dietetic Association, vol. 102, no. 7, pp. 924-929, 2002.

[23] J. Bhattacharya, J. Currie, and S. Haider, "Poverty, food insecurity, and nutritional outcomes in children and adults," Journal of Health Economics, vol. 23, no. 4, pp. 839-862, 2004.

[24] J. T. Cook, D. A. Frank, C. Berkowitz et al., "Food insecurity is associated with adverse health outcomes among human infants and toddlers," Journal of Nutrition, vol. 134, no. 6, pp. 1432-1438, 2004.
[25] S. Psaki, Z. A. Bhutta, T. Ahmed et al., "Household food access and child malnutrition: results from the eight-country MALED study," Population Health Metrics, vol. 10, no. 1, article 24, 2012.

[26] D. M. Matheson, J. Varady, A. Varady, and J. D. Killen, "Household food security and nutritional status of Hispanic children in the fifth grade," The American Journal of Clinical Nutrition, vol. 76, no. 1, pp. 210-217, 2002.

[27] M. Hackett, H. Melgar-Quiñonez, and M. C. Álvarez, "Household food insecurity associated with stunting and underweight among preschool children in Antioquia, Colombia," Revista Panamericana de Salud Publica, vol. 25, no. 6, pp. 506-510, 2009.

[28] H. C. Gooding, C. E. Walls, and T. K. Richmond, "Food insecurity and increased BMI in young adult women," Obesity, vol. 20, no. 9, pp. 1896-1901, 2012.

[29] W. R. Leonard, "Household-level strategies for protecting children from seasonal food scarcity," Social Science and Medicine, vol. 33, no. 10, pp. 1127-1133, 1991.

[30] R. B. Thomas and T. L. Leatherman, "Household coping strategies and contradictions in response to seasonal food shortage," European Journal of Clinical Nutrition, vol. 44, supplement 1, pp. 103-111, 1990.

[31] M. T. Ruel, "Is diversity an indicator of food security or dietary quality? A review of measurement issues and research needs," FCND Discussion Paper No 140, International Food Policy Research Institute, Washington, DC, USA, 2002.

[32] A. Onyango, K. G. Koski, and K. L. Tucker, "Food diversity versus breastfeeding choice in determining anthropometric status in rural Kenyan toddlers," International Journal of Epidemiology, vol. 27, no. 3, pp. 484-489, 1998.

[33] M. Arimond, D. Wiesmann, E. Becquey et al., "Simple food group diversity indicators predict micronutrient adequacy of women's diets in 5 diverse, resource-poor settings," Journal of Nutrition, vol. 140, no. 11, pp. 2059S-2069S, 2010.

[34] UNICEF, Strategy for Improved Nutrition of Children and Women in Developing Countries: A Policy Review, UNICEF, New York, NY, USA, 1990.

[35] L. Dubois, A. Farmer, M. Girard, and M. Porcherie, "Family food insufficiency is related to overweight among preschoolers," Social Science and Medicine, vol. 63, no. 6, pp. 1503-1516, 2006.

[36] P. H. Casey, P. M. Simpson, J. M. Gossett et al., "The association of child and household food insecurity with childhood overweight status," Pediatrics, vol. 118, no. 5, pp. e1406-e1413, 2006.

[37] D. Rose and J. N. Bodor, "Household food insecurity and overweight status in young school children: results from the early childhood longitudinal study," Pediatrics, vol. 117, no. 2, pp. 464-473, 2006.

[38] K. K. Saha, E. A. Frongillo, D. S. Alam, S. E. Arifeen, L. Å. Persson, and K. M. Rasmussen, "Household food security is associated with growth of infants and young children in rural Bangladesh," Public Health Nutrition, vol. 12, no. 9, pp. 15561562, 2009.

[39] A. Osei, P. Pandey, D. Spiro et al., "Household food insecurity and nutritional status of children aged 6 to 23 months in Kailali District of Nepal," Food and Nutrition Bulletin, vol. 31, no. 4, pp. 483-494, 2010.

[40] M. Savy, Y. Martin-Prével, P. Traissac, S. Eymard-Duvernay, and F. Delpeuch, "Dietary diversity scores and nutritional status of women change during the seasonal food shortage in rural Burkina Faso," Journal of Nutrition, vol. 136, no. 10, pp. 2625$2632,2006$. 
[41] N. I. Larson and M. T. Story, "Food insecurity and weight status among U.S. children and families: a review of the literature," The American Journal of Preventive Medicine, vol. 40, no. 2, pp. 166173, 2011.

[42] Z. M. Shariff and G. L. Khor, "Obesity and household food insecurity: evidence from a sample of rural households in Malaysia," European Journal of Clinical Nutrition, vol. 59, no. 9, pp. 1049-1058, 2005.

[43] M. C. Gulliford, D. Mahabir, and B. Rocke, "Food insecurity, food choices, and body mass index in adults: nutrition transition in Trinidad and Tobago," International Journal of Epidemiology, vol. 32, no. 4, pp. 508-516, 2003.

[44] J. Sobal and A. J. Stunkard, "Socioeconomic status and obesity: a review of the literature," Psychological Bulletin, vol. 105, no. 2, pp. 260-275, 1989. 

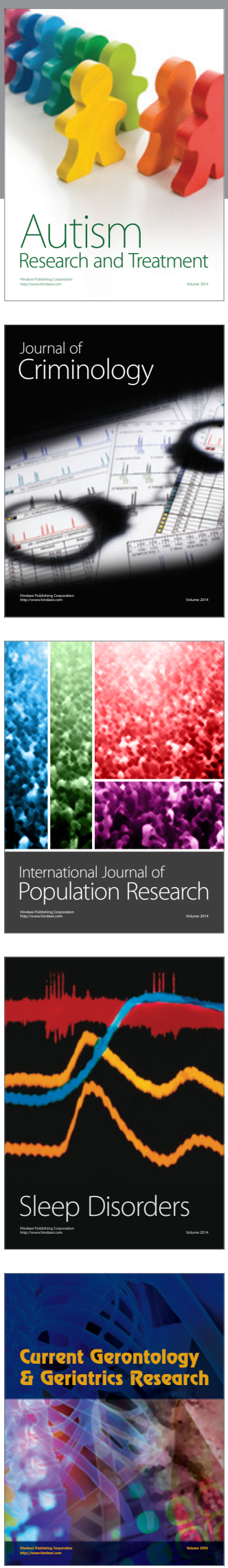
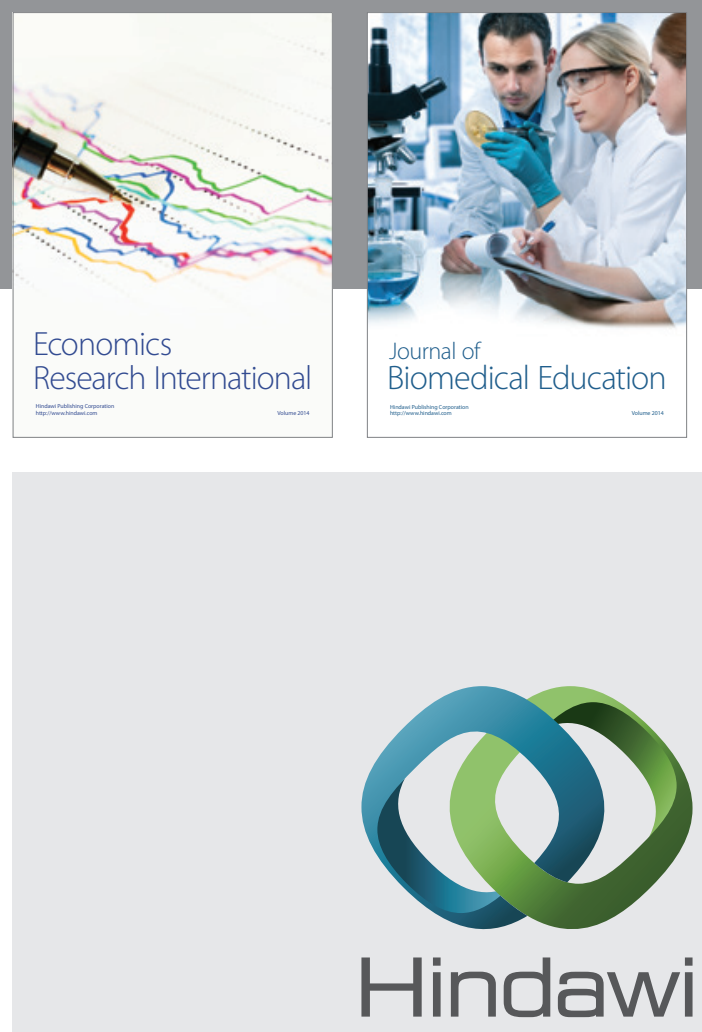

Submit your manuscripts at

http://www.hindawi.com

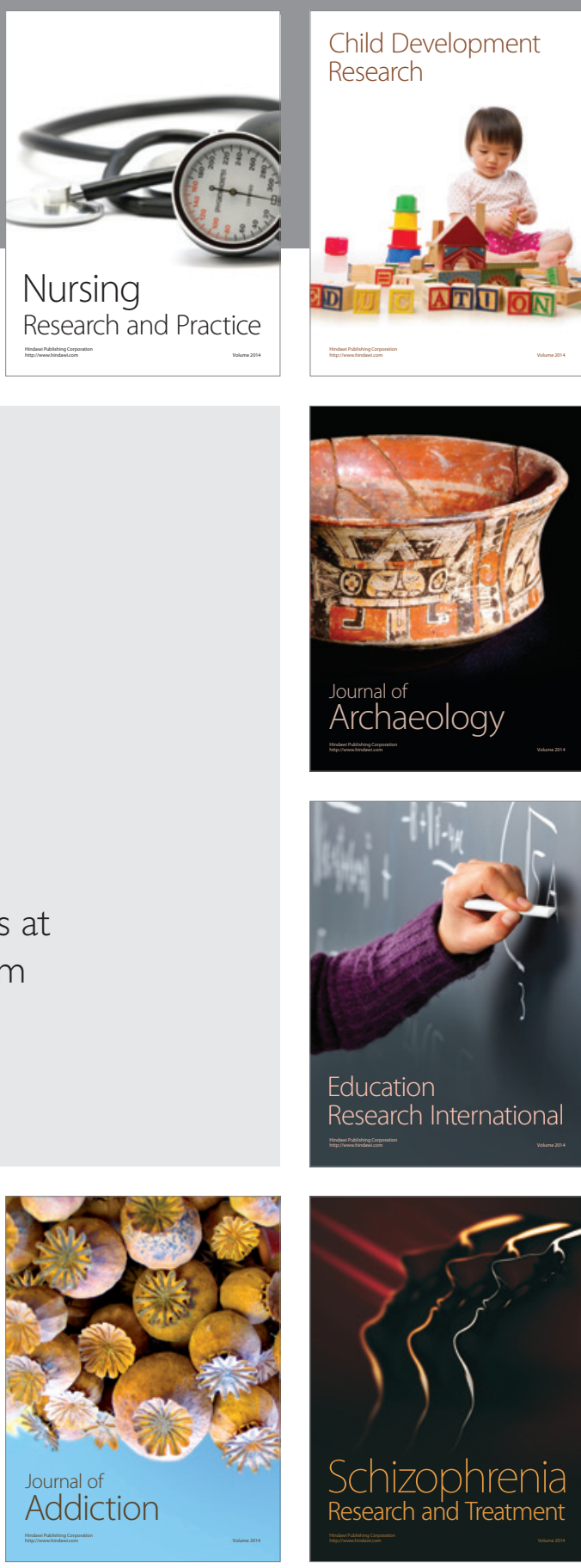

(D)
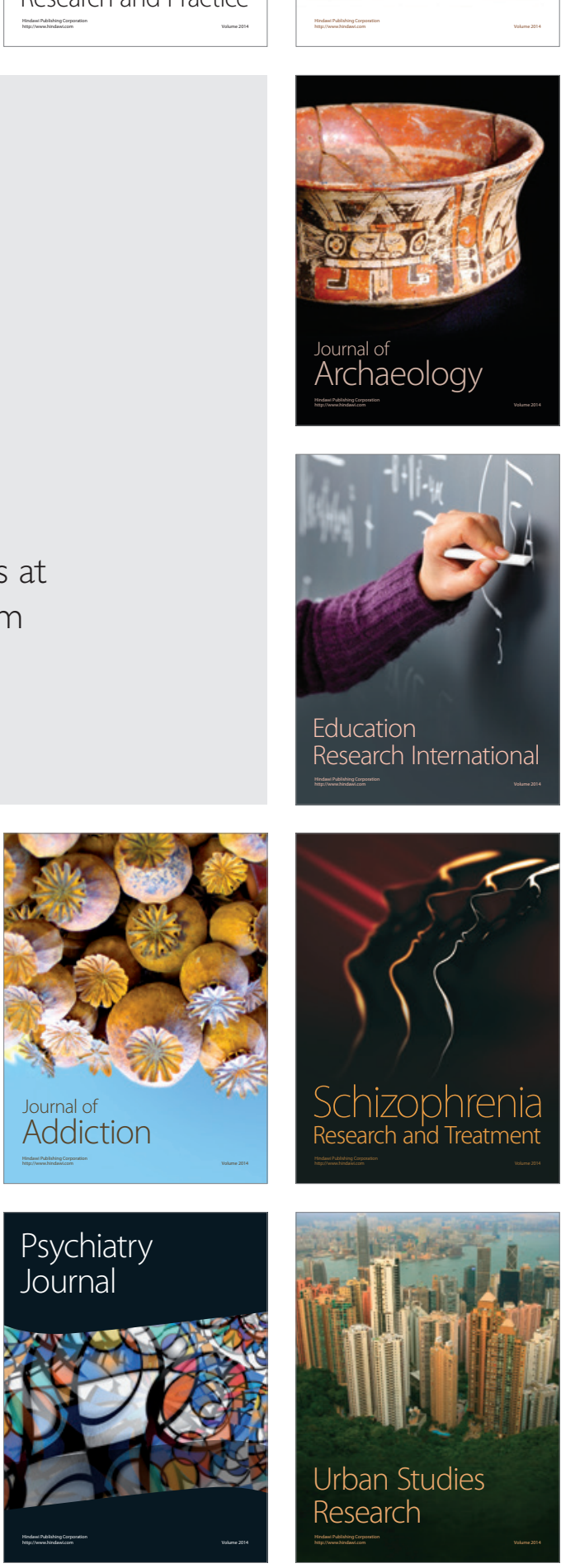